\title{
bmpkci is highly expressed in a resistant strain of silkworm (Lepidoptera: Bombycidae): Implication of its role in resistance to $\mathrm{BmDNV}-\mathrm{Z}$
}

\author{
Ke-Ping CHEN ${ }^{1}$, Hui-QIng CHEN ${ }^{1}$, Xu-Dong TANG ${ }^{2}$, QIn YAO ${ }^{1}$, Lin-Ling WANG ${ }^{1}$ and Xu HAN ${ }^{1}$
}

${ }^{1}$ Institute of Life Sciences, Jiangsu University, 301\# Xuefu Road, Zhenjiang 212013, P.R. China; e-mail: kpchen@ujs.edu.cn

${ }^{2}$ Institute of Life Sciences, Zhejiang University, Hangzhou, P.R. China

Key words. PKCI, Bombyx mori, virus-resistance, densonucleosis virus, fluorescent differential display, quantitative real-time PCR

\begin{abstract}
Using the fluorescent differential display technique, a special band named Bm541 was identified by screening for differentially expressed genes in the resistant silkworm strain Qiufeng, the susceptible strain Huaba35, and the near isogenic line $\mathrm{BC}_{6}$, which carries the resistant gene to Bombyx mori densonucleosis virus (BmDNV). After applying the 5'RACE technique with specially designed primers, a 1148 bp cDNA clone containing a 387 bp open reading frame (ORF) was obtained. This gene was registered in GenBank under the accession number AY860950. The deduced amino acid sequence showed a 73.1\% identity to the protein kinase C inhibitor (PKCI) of Drosophila pseudoobscura. In the deduced sequence of BmPKCI, the histidine triad (HIT) motif, which is essential for PKCI function, and the $\alpha$-helix region, which is conserved among the PKCI family, were present. The data from quantitative real-time PCR (QRT-PCR) suggest that the expression levels of bmpkci in $\mathrm{BC}_{6}$ and Qiufeng both with BmDNV-Z are significantly higher than those in Huaba35, which indicate that BmPKCI plays a role in resistance to BmDNV-Z.
\end{abstract}

\section{INTRODUCTION}

China has a history of over 5,000 years in raising silkworms, Bombyx mori (L.). At present, over 30 million farmer households are involved in sericultural production in China's over 10 provinces. Its output of silkworm cocoons, silk and silk fabrics account for over $70 \%$ of the world's total. Apart from China, sericulture is also practiced in Japan, the former Soviet Union and Brazil, etc. Silkworm viral diseases are important diseases causing great loss in sericulture, among which densonucleosis caused by densoviruses (DNVs) is one of the most disastrous. Therefore, the use of silkworm strains resistant to diseases is a prerequisite for more effective disease prevention. Certain silkworm strains are highly susceptible, while other strains are nonsusceptible or completely resistant to DNV even after being fed with a high concentration of virus inocula (Seki, 1984; Watanabe \& Maeda, 1978; Watanabe \& Maeda, 1981).

Densoviruses (DNVs) are autonomously replicating insect viruses of the family Parvoviridae (Siegl \& Tratschin, 1987). BmDNVs multiply only in the nuclei of the columnar cells of the larval midgut epithelium (Garzon \& Kurstak, 1976). The parvoviruses are the smallest viruses to contain a DNA genome and require factors from the host cell and (or) helper virus for efficient viral replication (Abe et al., 1987; Goldsmith et al., 2005; Watanabe et al., 1986). These characteristics are very similar to those of human parvoviruses, which suggests replication mechanism similarities between BmDNV-1 and human parvoviruses (Hayakawa et al., 1997).

BmDNVs comprise several strains, such as Ina virus, Saku virus and Yamanashi virus. As classified by Watanabe et al. (1986), Ina virus belongs to the DNV-1 type, whereas the Saku and Yamanashi viruses belong to
DNV-2 type. A special type of BmDNV named BmDNV-Z was isolated in Zhenjiang, China, and has a common antigen and is very similar to BmDNV-2 (Iwashita \& Chun, 1982).

The silkworm resistance to BmDNV is inherited in a Mendelian fashion (Watanabe, 2002). Studies indicate that the nonsusceptibility to DNV-1 is controlled by two genes: one is $n s d-1$ (non-susceptibility to DNV-1), and the other is Nid-1(non-infection to DNV-1) (Eguchi et al., 1986). The recessive gene, $n s d-1$, is located at position 8.3 on the chromosome 21 of the silkworm (Eguchi et al., 1991). Nid-1 is dominant and is not located on chromosomes Z, 2, 12, or 17 (Eguchi et al., 1986). It was also found that a recessive gene ( $n s d-2)$ controls the nonsusceptibility of the larvae to DNV-2. The $n s d-2$ gene is located on a different chromosome from those of $n s d-1$ and Nid-1 genes (Abe et al., 1987). Hu et al. (1984) have shown that a third recessive gene, $n s d-Z$, controls nonsusceptibility to DNV-Z. This gene is located on chromosome 15 (Qin \& Yi, 1996) and the closest SSR marker linked to $n s d-Z$ was mapped at a distance of $4.4 \mathrm{cM}$ from $n s d-Z$ (Li et al., 2001, 2006).

Though significant progress has been made in identifying the location of the resistant genes to DNV in $B$. mori, little about the resistant genes have been cloned or characterized. If the resistant genes are obtained and used to rear homozygous $n s d-Z$ silkworm strains, it will greatly reduce the economic losses caused by DNV-Z. It may also help scientists to understand the mechanism of resistance or susceptibility and the relationship between silkworm and BmDNV-Z. The silkworm response upon DNV infection is of particular interest, especially the response of resistant compared to susceptible lines. Recently comparative gene expression techniques, such 
as differential display and quantitative real-time PCR, have been routinely used to examine changes in gene expression. Such methodologies provide useful ways of identifying differently expressed transcripts, because these can be examined simultaneously using only small quantities of RNA.

This paper examines gene expression simultaneously in infected and uninfected silkworm among a susceptible, a completely resistant and a near isogenic silkworm line, which inherits susceptible background but with the resistant gene. This approach will enable a distinction to be made between a general response to infection in susceptible silkworm and a resistant-specific response, by identifying altered gene expression that only occurs in the resistant silkworm upon exposure to infection.

\section{MATERIAL AND METHODS}

\section{Silkworm strains}

The silkworm strain Qiufeng ( $n s d-Z / n s d-Z$ ), which is resistant to BmDNV-Z, and Huaba35 strain $(+n s d-z /+n s d-z)$, which is susceptible to BmDNV-Z, were maintained by single pair matings. We constructed the near isogenic line $\mathrm{BC}_{6}$, by crossing females of cyclical backcross parent, Huaba35, with males carrying resistant genes of strain Qiufeng, which was used as the donor of resistant genes. First we crossed Huaba35 with males of strain Qiufeng. Then the $F_{1}$ generation was self-crossed. BmDNV-Z virus was inoculated into larvae of each self-crossed generation to screen for the individuals carrying the resistant gene. Subsequently, we used the individuals carrying resistant genes to cross with the strain Huaba35. The backcrosses were conducted for 6 generations (Fig. 1). Thus $\mathrm{BC}_{6}$ strain also carries the recessive gene (nsd-Z/nsd-Z). In theory, the inherited background of $\mathrm{BC}_{6}$ has $99.9 \%$ identity with Huaba35, the susceptible strain (Chen, 2000).

In order to investigate the mortality of silkworm, DNV-Z was fed to second instar larvae of three silkworm strains, Qiufeng, Huaba35 and the near isogenic line $\mathrm{BC}_{6}$. For each strain, 100 larvae were taken and the controls were fed with artificial diet treated with the same volume of water.

\section{Virus inoculation}

$0.5 \mathrm{~g}$ dried silkworm midgut that contained DNV-Z was ground in $25 \mathrm{~mL}$ distilled water until it turned into a dense solution. The solution was filtered through gauze and centrifuged at $3000 \mathrm{rpm}$ for $20 \mathrm{~min}$. After adding $25 \mathrm{~mL} 2 \mathrm{M}$ acetic acid to the supernatant, the solution was incubated at $25^{\circ} \mathrm{C}$ for $30 \mathrm{~min}$, followed by adjustment to $\mathrm{pH} 7.0$ and progressive dilution to $0.1 \%$ solutions of tissue.

All larvae of three silkworm strains, Qiufeng, Huaba35 and the near isogenic line $\mathrm{BC}_{6}$, were raised to the fifth instar on artificial diet. For each strain, 30 newly metamorphosed 5th instar larvae were taken and fed with artificial diet treated with $0.1 \%$ BmDNV-Z and the controls were fed with artificial diet treated with the same volume of water. All of the infected silkworms were checked for DNV by immunoperoxidase staining methods (Qian et al., 1989). 30 inoculated individuals and 30 controls from each strain (Qiufeng, Huaba35 and $\mathrm{BC}_{6}$ ) were sampled and their midguts used for isolating RNA $72 \mathrm{~h}$ after the virus inoculation. The total RNA from the midguts was then used for fluorescent differential display and quantitative real-time PCR procedures.

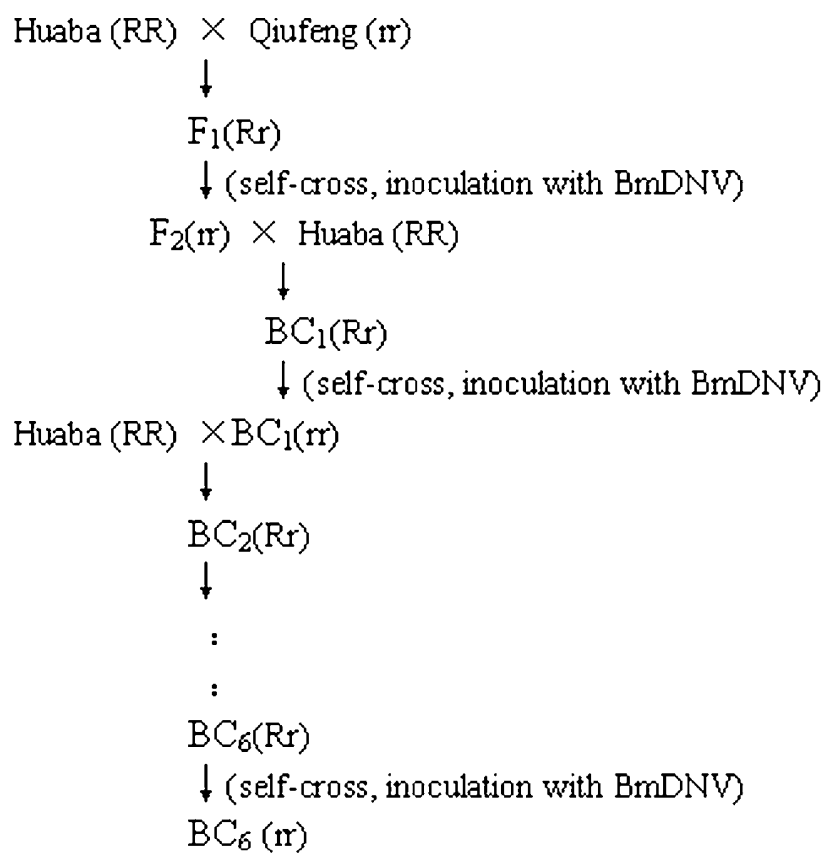

Fig. 1. Establishment of near isognic lines $\mathrm{BC}_{6} . \mathrm{BC}_{1}$ and $\mathrm{BC}_{2}$ stand for the first and second backcrosses and so forth. $\mathrm{R}-$ the dominant gene; $r$ - the recessive gene.

\section{Fluorescent differential display analysis}

Fluorescent differential display (FDD) analysis was performed with a commercial kit (RNA spectra Kit, GenHunter, Nashville, TN) according to the method described by the manufacturer. $2 \mu \mathrm{g}$ of total RNAs was reverse-transcribed with MMLV reverse transcriptase and 3'-anchored oligoH-T11G primer to yield the first strand of cDNA. Subsequently, $2 \mu \mathrm{l}$ of first-strand cDNA was used for PCR reaction containing 1 unit Taq polymerase (Qiagen Co., Hilden, Germany), $50 \mu \mathrm{M}$ of each $\mathrm{dNTP}, 0.5 \mu \mathrm{M}$ of arbitrary primer, $0.5 \mu \mathrm{M}$ of fluorescein isothiocyanate-labelled 3'-anchored oligoH-T11G (FH-T11G) primer and $2 \mu 1$ of $10 \times$ PCR buffer. The thermal cycling profile was as follows: 40 cycles of $94^{\circ} \mathrm{C}$ for $30 \mathrm{~s}, 40^{\circ} \mathrm{C}$ for $2 \mathrm{~min}$ and $72^{\circ} \mathrm{C}$ for $1 \mathrm{~min}$, followed by final extension at $72^{\circ} \mathrm{C}$ for $5 \mathrm{~min}$. Each PCR product was electrophoresed in a $6 \%$ denatured polyacrylamide gel in $1 \times$ TBE buffer. FDD gel was scanned with the FMBIO II system (Hitachi Genetics, Tokyo, Japan).

\section{Cloning and sequencing}

Differential display bands of interest were cut out of the gel, eluted, and reampified. PCR products were subcloned into pMD18-T vectors (TaKaRa, Dalian, China) and confirmed by EcoR I digestion according to the manufacturer's instruction. The plasmids were expanded in Escherichia coli, harvested and the subsequent DNA sequencing of the PCR products was performed on a CEQ8000 DNA sequencer (Beckman Coulter, Fullerton, CA, USA).

\section{5'-RACE}

The 5' end of the complete cDNA was obtained by a modified RACE method using a SMART RACE cDNA Amplification Kit (Clontech, CA, USA) according to the manufacturer's instructions. A template first-strand cDNA was synthesized from the total RNA extracted from the silkworm midguts. Specific primers for 5'- were designed based on the sequence of the FDD fragment: 5'-agcaatacggtcagcaaacaaaacaat-3'. The 5'RACE product showed a major band when subject to electro- 
phoresis in $1 \%$ agarose gel, which was sub-cloned into vector pMD18-T and sequenced.

\section{Reverse transcription-polymerase chain reaction analysis}

The mRNA expression levels in different strains and tissues were measured by semiquantitative reverse transcription PCR (RT-PCR). Total RNA was isolated from the midgut of the susceptible silkworm strains, Huaba35 and Jingsong, and the resistant strains, Qiufeng and Dong34, and from various tissues, including midgut, fat bodies, silk gland, testis, ovary and hemocytes of fifth-instar larvae using TRIzol reagent (Invitrogen, Carlsbad, USA). The first-strand cDNA was synthesized from 2 $\mu \mathrm{g}$ of total RNA in a final volume of $25 \mu \mathrm{L}$ containing $200 \mathrm{U}$ MMLV reverse transcriptase (Promega, Madison, USA). PCR was performed on the resulting cDNAs using two bmpkci genespecific primers, bmpkci-F (5'-agcgtttaccaccttcacattcata-3' and bmpkci-R (5'agcaatacggtcagcaaacaaaacaat -3' (GenBase Co, Shanghai, China). The constant expressed gene, $\beta$-actin, was used as the internal control. Two primers AF (forward: 5'ggatgtccacgtcgcacttca-3') and AR (reverse 5'gegcggetactcgttcactacc-3') were designed on the basis of the sequence of the $B$. mori actin gene (Accession number: U49854). RT-PCR was carried out in a Gene Amp2400 System thermocycler (Perkin-Elmer Cetus, Emeryville, CA, USA) in a $25 \mu \mathrm{L}$ reaction volume containing $2.5 \mu \mathrm{L}$ of $10 \times$ PCR buffer (with $\mathrm{Mg}^{2+}$ ), $2 \mu \mathrm{L}$ of dNTP mix $(2.5 \mathrm{mM}), 1 \mu \mathrm{L}$ of each primer $(10 \mu \mathrm{M}), 0.2 \mu \mathrm{L}$ Taq polymerase $(5 \mathrm{U} / \mu \mathrm{L})$ (TaKaRa, Dalian, China), $1 \mu \mathrm{L}$ of cDNA (30 ng/ $\mu \mathrm{L})$, and PCR-grade water. The cycling protocol was 1 cycle of $94^{\circ} \mathrm{C}$ for $2 \mathrm{~min}, 30$ cycles of $94^{\circ} \mathrm{C}$ for $15 \mathrm{~s}, 61^{\circ} \mathrm{C}$ for $40 \mathrm{~s}$ and $72^{\circ} \mathrm{C}$ for $15 \mathrm{~s}$, and a final extension step at $72^{\circ} \mathrm{C}$ for $10 \mathrm{~min}$. The PCR products were electrophoresed in $1.5 \%$ agarose gel stained with ethidium bromide. The optical densities of the amplified bands were analyzed using AlphaImager 1220 V5.5. Software (AlphaInnotech, CA, USA)

\section{Quantitative real-time PCR and data analysis}

Quantitative real-time PCR (QRT-PCR) information was obtained using Mx 3000P (Stratagene, San Diego, CA) for thermal cycling, real-time fluorescence detection and subsequent analysis. The cDNA for gene-specific RT-PCR assays were synthesized as described above. The $B$-actin was used as the calibrator sample. Carboxy-X-rhodamine (ROX) dye was used as the reference dye for normalization of the reactions. QRT-PCR was carried out in a $25-\mu 1$ reaction volume containing $12.5 \mu 1$ of SYBR Green I Mix (Takara), $0.5 \mu \mathrm{M}$ of each of the primers and $0.5 \mu 1$ ROX Reference Dye II $(5 \times)$ and cDNA obtained from $10 \mathrm{ng}$ of total RNA. The two-step amplification protocol consisted of $2 \mathrm{~min}$ at $94^{\circ} \mathrm{C}$ followed by target amplication via 40 cycles at $94^{\circ} \mathrm{C}$ for $15 \mathrm{~s}, 61^{\circ} \mathrm{C}$ for $40 \mathrm{~s}$ and $72^{\circ} \mathrm{C}$ for $15 \mathrm{~s}$. Detection of fluorescent product was carried out after the last step of each cycle. Following the final amplification cycle, a melting curve was acquired by one cycle of heating to $95^{\circ} \mathrm{C}$, cooling to $65^{\circ} \mathrm{C}$ at $20^{\circ} \mathrm{C} \mathrm{s}^{-1}$ and slowly heating to $95^{\circ} \mathrm{C}$ at $0.1^{\circ} \mathrm{C} \mathrm{s}^{-1}$ with continuous measurement of fluorescence at 520 $\mathrm{nm}$. After PCR, the absence of unwanted by-products was confirmed by automated melting curve analysis and agarose gel electrophoresis of the products. The transcript levels of the target fragment were normalized with $\beta$-actin transcript levels in the same samples.

The threshold cycle $\left(C_{\mathrm{t}}\right)$ value was defined as the number of PCR cycles required for the fluorescence signal to exceed the detection threshold value (background noise). The $C_{\mathrm{t}}$ values correlated with the initial amount of specific template (Higuchi et al., 1993). The $C_{\mathrm{t}}$ values of both the calibrator and the samples of interest are normalized to the housekeeping gene. The comparative $C_{\mathrm{t}}$ method is also known as the $2^{-\Delta \Delta C_{\mathrm{t}}}$ method, where $\Delta \Delta C_{\mathrm{t}}=\Delta C_{\mathrm{t} \text { sample }}-\Delta C_{\mathrm{t} \text { reference }}$ (Livak \& Schmittgen, 2001). Here, $\Delta C_{\mathrm{t} \text { sample }}$ is the $C_{\mathrm{t}}$ value for any sample normalized to the $\beta$-actin and $\Delta C_{\mathrm{t}}$ reference is the $C_{\mathrm{t}}$ value for the calibrator also normalized to the $\beta$-actin. The data was analyzed using SPSS 13.0.

\section{Computer analysis of sequence data}

A homology search of the obtained DNA sequences against GenBank (http://www.ncbi.nlm.nih.gov) was performed. cDNA was aligned with genomic sequence of $B$. mori by using SIM4 (Florea et al., 1998) and Spidy to give a view of the actual splicing sites. All possible ORFs were translated to amino acid sequences by Expasy Translate tool. Secondary structure prediction was done by PSIPRED (Bryson et al., 2005) protein structure prediction server (http://bioinf.cs.ucl.ac.uk/psipred/). Direct comparisons between two sequences were performed using the NEEDLE global alignment program (Needleman \& Wunsch, 1970) within the EMBOSS suite of programs (http://www.uk.embnet.Org/Software/EMBOSS/) from which overall percentage values were recorded.

\section{RESULTS}

\section{Resistance identification of Qiufeng, Huaba35, and the near isogenic line $\mathrm{BC}_{6}$}

For each strain, 100 second instar larvae were taken and fed with $0.1 \%$ BmDNV-Z, and the controls were treated with the same volume of water. Normally, silkworms that are susceptible to BmDNV-Z develop very slowly and cannot survive through the third instar. Incidence of disease indicated that $98 \%$ of Huaba35 were susceptible and all others resistant (Table 1). This is consistent with previous results showing that resistance to $\mathrm{DNV}-\mathrm{Z}$ is recessive (Hu et al., 1984).

\section{Fluorescent differential display}

To identify genes associated with the expressions of resistant genes, we compared the mRNA expression patterns in midguts of different silkworm strains using the FDD technique. A combination of 6 arbitrary primers and

TABLE 1. Results of inoculation of silkworm larvae with BmDNV-Z and its control.

\begin{tabular}{cccccc}
\hline Treatments & Strain & No. inoculated & No. infected with BmDNV-Z & No. of survivors & Incidence of disease (\%) \\
\hline \multirow{4}{*}{ Inoculation } & Qiufeng & 100 & 0 & $95^{*}$ & 0 \\
& Huaba35 & 100 & 98 & 2 & 98 \\
& $\mathrm{BC}_{6}$ & 100 & 0 & $96^{*}$ & 0 \\
\hline \multirow{5}{*}{ Controls } & Qiufeng & 100 & 4 & 100 & 0 \\
& Huaba35 & 100 & 0 & 96 & 4 \\
& $\mathrm{BC}_{6}$ & 100 & $97^{*}$ & 0 \\
\hline
\end{tabular}

*The number of survivors decreased because some were infected with other diseases. 


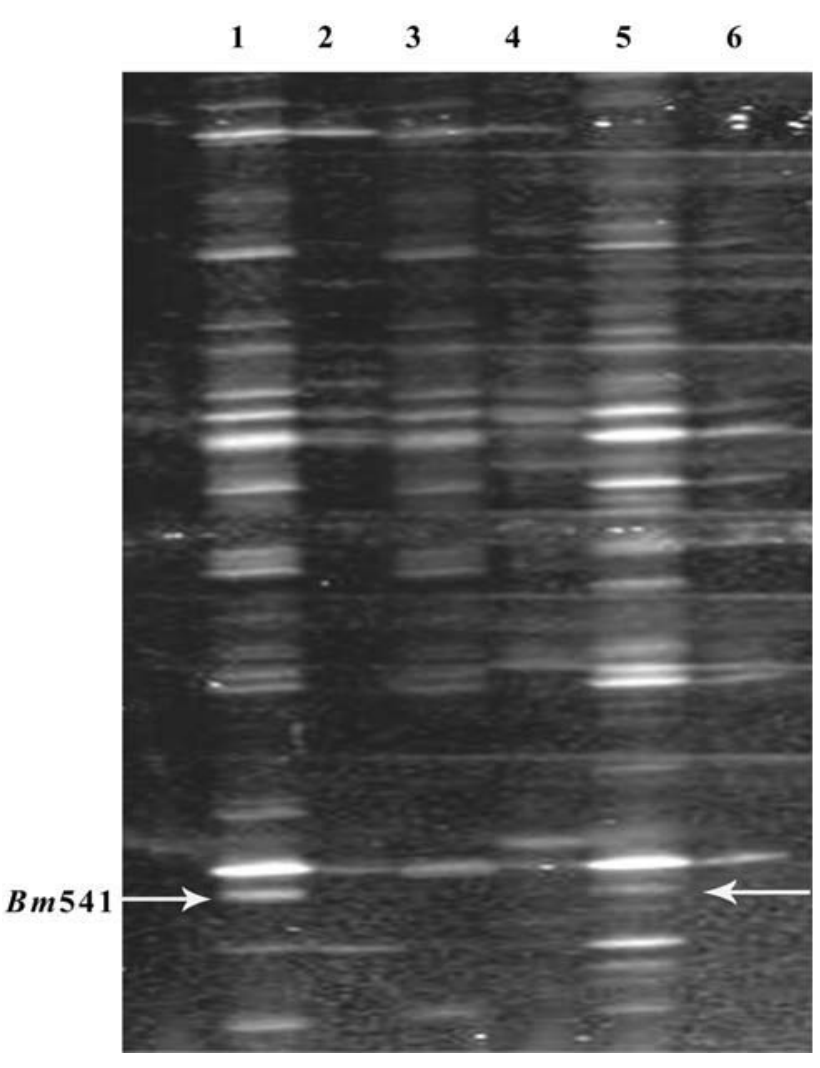

Fig. 2. Differential displayed bands of FDD analysis. Differentially expressed gene is indicated by arrow. Lane 1, 3, 5 represent treatments $\mathrm{BC}_{6}$, Huaba35, and Qiufeng infected with BmDNV-Z, respectively. Lane 2, 4, and 6 represent the respective controls.

an anchored oligo $(\mathrm{dT})$ primer were used to produce the cDNA for the differential display analysis. FDD profiles were produced from the pooled RNA samples in the six categories: $\mathrm{BC}_{6}$ inoculated, $\mathrm{BC}_{6}$ control, Huaba35 inoculated, Huaba35 control, Qiufeng inoculated and Qiufeng control. The fragments that were only present in the profiles from inoculated resistant silkworm (Fig. 2, lane 1 and 5) and absent from all control silkworm profiles and inoculated susceptible silkworm profiles were identified. These indicated a response unique to the resistant silkworm strain. Such diferentially expressed bands were extracted from the gels and used for DNA cloning and sequencing.

A homology search of the obtained DNA sequences against GenBank was performed. From a database analysis of 20 transcripts with different expression patterns, in this study we selected the differentially expressed band Bm541 present only in the inoculated resistant silkworm profiles as possible gene determining resistance to BmDNV-Z, based on homology search. The differentially expressed band was analyzed using QRTPCR to verify the FDD results.

\section{Full-cDNA sequence}

After 5'-RACE we sequenced a clone with a $880 \mathrm{bp}$ fragment inserted (data not shown), which contains a 384 bp ORF. Using the Megalign software program (DNASTAR Inc., Madison, USA) we ligated the acgcggggaaacatggcggacggtgaggtgaaactcgcacaaactgccgcaccaggcggt

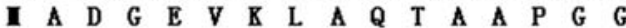
gatacaatct tgggaaaat at tacgtaaagaaatccctgcaaat t tcatt tacgaagac $\begin{array}{llllllllllllllllllll}\text { D } & \text { T } & \text { I } & \text { F } & \text { G } & \text { K } & \text { I } & \text { L } & \text { R } & \text { K } & \text { E } & \text { I } & \text { P } & \text { A } & \text { N } & \text { F } & \text { I } & \text { Y } & \text { E } & \text { D }\end{array}$ gaacaatgcgtagcgttcaatgatgtgaacccacaagctcctactcatgtat tggtgata $\begin{array}{lllllllllllllllllllll}\text { E } & \mathbf{Q} & \mathbf{C} & \mathbf{V} & \mathbf{A} & \mathbf{F} & \mathbf{N} & \mathbf{D} & \mathbf{V} & \mathbf{N} & \mathbf{P} & \mathbf{Q} & \mathbf{A} & \mathbf{P} & \mathbf{T} & \text { (H) } & \mathbf{V} & \mathbf{L} & \mathbf{V} & \mathbf{I}\end{array}$ ccaaggaagcctattccacagctctcgctggctgatgatactgatgaacagttgttagga $\begin{array}{llllllllllllllllllll}\text { P } & R & \text { K } & \text { P } & \text { I } & \text { P } & \text { Q } & \text { L } & \text { S } & \text { L } & \text { A } & \text { D } & \text { D } & \text { T } & \text { D } & \text { E } & \text { Q } & \text { L } & \text { L } & \text { G }\end{array}$ catcttctaattgttgcccgtaaact tgctgcccagctaggcctggacaagacaggcttc $\begin{array}{llllllllllllllllllll}\text { H } & \text { L } & \text { L } & \text { I } & \text { V } & \text { A } & \text { R } & \text { K } & \text { L } & \text { A } & \text { A } & \text { Q } & \text { L } & \text { G } & \text { L } & \text { D } & \text { K } & \text { T } & \text { G } & \text { F }\end{array}$ cgcctcgttgttaacgatggaaagaatggcgcccaaagcgtt taccaccttcacat tcat $\begin{array}{llllllllllllllllllll}R & \text { L } & \text { V } & \text { V } & & \text { N } & \text { D } & \text { G } & \text { K } & \text { N } & \text { G } & \text { A } & \text { Q } & \text { S } & \text { V } & \text { Y } & \text { H } & \text { L } & \text { (H) } & \text { I (H) (H) }\end{array}$ atcctcggaggaaggcagatgcagtggccacctggctaatt tattatctatagcaatttg

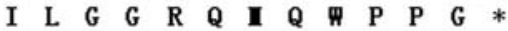

agaat t catcgcaaaat tagcagtct tcgaaat tagcagtct t agtt tgaaag agct aagcaat t t t aat at aaaactgat aact tacctggtgtgaat tat at gagt t t t t taaa gcgtcaccaccaagaaaag tcat taagaat aat aact t tat atgtat aagtat tacaacc t tgttgtatat aaaatgt t taaaaact tgaatatgatctat t t t tgct taaactggaatg ctaat tgcatagttt taaat tggat aacaaagataccccaagactcgatcat tt tgatc ctgatatagaat tatatacatcaacaact acct taaat tgt tcatcaagttgggat t tgt ccctat tcaccctgttt tagggtaat taat tat tactaatg aatttagtagt tacttta agggtgatgtt tatatttttatttgaccact cctaataagtaaat tacaaaact aa aat a aaaatgggtgaaatccgt aact tgaat t taatgaat tgtt t gtttgctgaccg tat tgct t t cacgcctacat tgacgggtatacagat tggtcactcacacaactaagggtg gcgcccagtcgtact t tgcaagaact atagctat taat tacgt tatgactaggctaaagg atggaaat taat t t tgcgatgaggtcatgccgaagt tgaat t taat aaaaat at tgta attgcaaaaaaaaaa

Fig. 3. Genomic sequence of bmpkci. The putative translation is given below the nucleotide sequence. The initiate and stop codes are framed and the putative polyadenylation signals are underlined. The HIT motif containing the conserved His triad is double-underlined, and the three His residues involved in the binding of zinc are circled.

sequence of FDD and RACE into a full-length cDNA. The full-length sequence measured $1145 \mathrm{bp}$, the first 12 bp and the last $746 \mathrm{bp}$ of which constituted the 5' and 3' UTR, respectively. Within the 3' UTR, a typical polyadenylation signal was present between nucleotides 1125 and 1130. Two sites associated with mRNA instability (ATTTA) were also present within the 3' UTR sequence (Fig. 3). The remaining 387 nucleotides (including the stop codon TGA) encoded a putative peptide of 128 amino acids with characteristics of a conserved domain HxHxHxx (Brenner et al., 1997; Seraphin, 1992), thus we named this gene bmpkci.

\section{RT-PCR analysis of the PP-BP gene expression}

To determine the strains and tissue distribution of the bmpkci transcripts, a semiquantitative RT-PCR analysis was performed. RT-PCR detected bmpkci expression in the midgut of $\mathrm{BC}_{6}$, Huaba35, Jingsong, Qiufeng, and Dong34. Stronger products were apparent in both inoculated resistant strains, $\mathrm{BC}_{6}$, Qiufeng, and Dong34 (Fig. 4). The results also indicated that bmpkci was expressed almost exclusively in the midgut tissue of both susceptible and resistant inoculated strains, $\mathrm{BC}_{6}$, Huaba35, and Qiufeng (Fig. 5). In all samples tested $\beta$-actin products were amplified, confirming that reverse transcription was successful. 


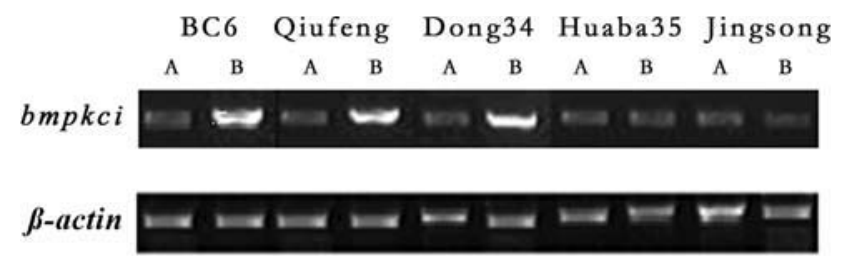

Fig. 4. mRNA expression of bmpkci in the midgut of different silkworm strains. A - treatment with water as control; B - treatment of the silkworms infected with BmDNV-Z.

\section{Quantitative real-time PCR}

The specificity of quantitative real time PCR results was assessed by dissociation curve analysis and by agarose gel electrophoresis. The melting curves show that two specific products, bmpkci and $\beta$-actin, were amplified with a $T \mathrm{~m}$ of $89^{\circ} \mathrm{C}$ and $79^{\circ} \mathrm{C}$, respectively (data not shown). The agarose gel shows a single band with the expected size of $286 \mathrm{bp}$ (data not shown). These results mean that the bmpkci real-time PCR assay was genespecific and that the results were not confounded by nonspecific amplification or primer-dimer.

The relative expressions of bmpkci were analysed using the $2^{-\Delta \Delta C t}$ method. The differentially expressed band bmpkci thought to be associated with resistance to BmDNV-Z were analyzed using QRT-PCR. In the inocu-

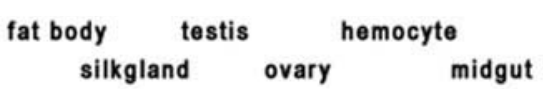

BmPKCI in BC6

BmPKCl in Huaba35

BmPKCl in Qiufeng

$\beta$-actin in Huaba35

$\beta$-actin in Qiufeng

$\beta$-actin in BC6

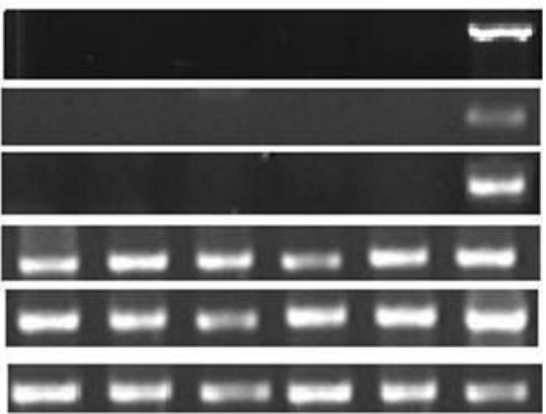

Fig. 5. mRNA expression of bmpkci in different tissues. The silkworm strains were inoculated with BmDNV-Z.

lated resistant strains, $\mathrm{BC}_{6}$ and Qiufeng exhibited a markedly higher expression level than their controls. Moreover, the expression levels of the resistant strains $\mathrm{BC}_{6}$ and Qiufeng treated with BmDNV-Z were also higher than the susceptible inoculated strain Huaba35, $5.426 \pm 0.223,3.160 \pm 0.778$, and $1.266 \pm 0.454$, respectively. In the susceptible strain, no difference was observed between the Huaba35 control and that treated with DNV-Z.

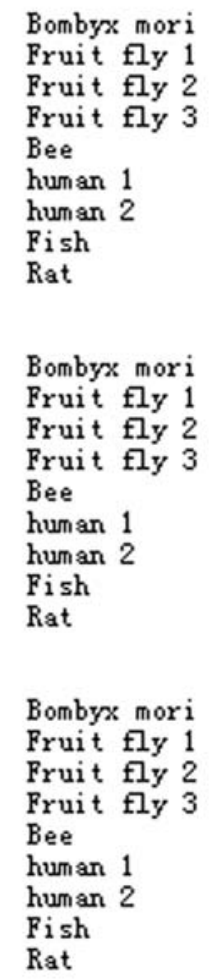

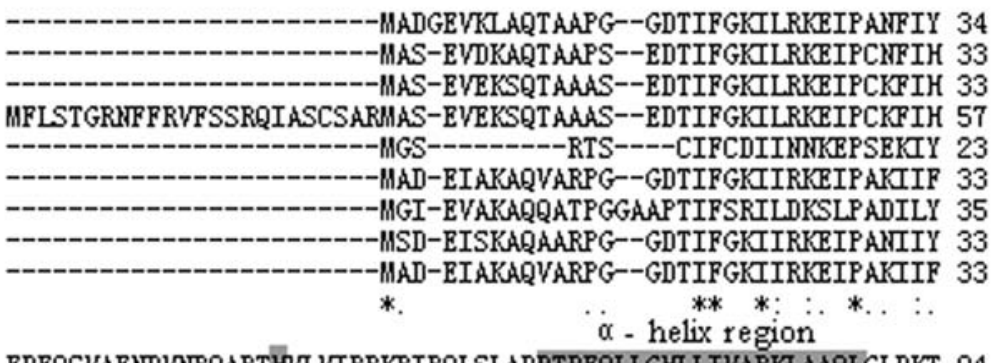

EDEQCVAFNDVRPQAPTHVVIPRKPIPQLSLADDTDEQLLGHLIVARKLAAQLGLDKT 94 EDDKCVAFHDVAPQAPTHFLVIPRKPIAQLSLAEDGDGELLGHULVGRKVAKDLGLEK- 92 EDDKCVAFFDVAPQAPTHFLVIPRKPIAQLSLAEDGDADLLGHUMLVGRKVAKELGLAD- 92 EDDKCVAFFWVAPQAPTHFLVIPRKPIAQLSLAEDGDADLLGHULVGRKVAKELGLAD- 116 EDNYVTCIKDIHPVSTHYYLILPKEHIRNAKQLKPEHSELYDKMLAAIDIISQKQGLDR- 82 EDDRCLAFHISPQAPTHFLVIPKKHSQISVAEDDDESLLGHIIVGKKCAADLGLRK- 92 EDQQCLVFRDVAPQAPVIFLVIPKKPIPRISQAEEEDQQLLGHLILVAKQTAKAEGLGD- 94 EDEQCLAFHDISPQAPTHFLVIPKKPIVRLSEAEDSDESLLGHUIVGKKCAARLGLTN- 92 EDDRCLAFHDISPQAPTHFLVIPKKYISQISAAEDDDESLLGHUIVGKKCAADLGLKK- 92 **: $\quad \therefore * * *$ HxHxHxx domain

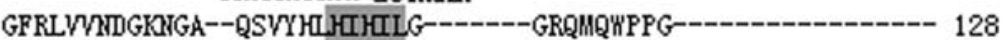

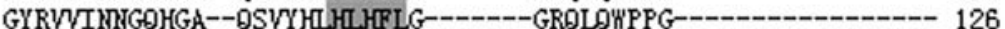

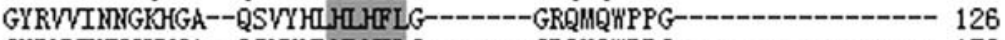

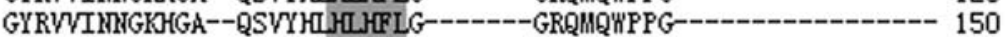
---AVTRTGFHWPPFNTVSHLLHVISPISHIKFYKRYMYEPGSCWFVSTDYVKSRLODN 139

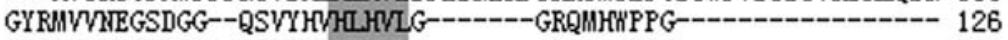

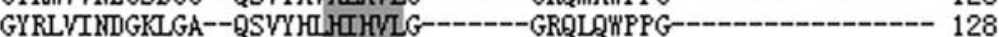

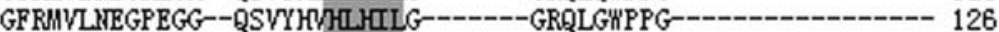

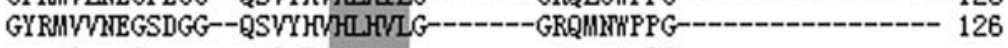

Fig. 6. CLUSTAL X (1.83) generated multiple alignment comparing BmPKCI with other vertebrate and arthropod PKCI peptides. The $\alpha$-helix region is indicated and the conserved His triad is boxed. The gaps in the alignment are represented with a dash (-). Conservation of amino acid identity is indicated in the consensus line with an asterisk whereas ":" and "." show high and low levels of amino acid similarity, respectively. The amino acids sequences for human1 (CAG33329), human2 (AAL40394), rat (P62959), fish (BAA94873), fruit fly1 (EAL33061), fruit fly2 (NP_722836), fruit fly3 (NP_608711) and Bombyx mori (AAW55666) and bee (XP_625181) are deposited in Genbank amino sequence database with the accession numbers shown in parentheses. 


\section{Analysis of the amino acid sequence}

Multiple alignments shows the predicted conserved domain HxHxHxx aligns exactly with confirmed conserved domain positions within other PKCI molecules (Fig. 6). When the deduced sequences of this region of PKCI for human, rat, fish, fruit fly, bee, and the corresponding region of $\mathrm{BmPKCI}$, were analyzed for the secondary structure by PSIPRED, all of these sequences were predicted to form $\alpha$-helices (Fig. 6). The highly conserved $\alpha$-helix region has been suggested to be the site of intermolecular contact in the formation of a homodimer of PKCI (Lima et al., 1996).

Comparison of the BmPKCI sequence with published PKCI sequences using the NEEDLE program showed that this molecule was closest in identity to Arthropoda PKCI molecules. The BmPKCI shared 73.1\% amino acid identity to Drosophila pseudoobscura (EAL33061), and similarity to two D. melanogaster isoforms was also high (59.9-70.7\% amino acid identity to D. melanogaster isoform A and D. melanogaster isoform B, respectively).

\section{DISCUSSION}

Differential display is a powerful tool for identifying genes that are differentially expressed under various conditions. However, the high percentage of false positives generated by differential display (as high as 85\%) has previously limited the potential of this method. Northern and reverse Northern have been used to identify and discard false positives (Callard et al., 1994; Zegzouti et al., 1997). Compared with the conventional methods, the recently developed real-time PCR assay is more sensitive and specific for isolating the true differential cDNAs without radioactive pollution.

In our study, the near isogenic line $\mathrm{BC}_{6}$ was constructed after 6 generations of backcross, self-cross, and artificial selection, which carries the recessive gene ( $n s d-\mathrm{Z} / n s d-Z$ ). In FDD analysis, the transcript level between the inoculated strains and the non-infected strains was different, although we used the same amount of RNA. The expressions in inoculated strains were higher than in their controls, which may indicated that the viral infection stimulated the expression of the genes related to defense or the expression cascade of resistant genes.

Using FDD analysis, we obtained the gene that was differentially expressed in resistant silkworm strains. The differential band that clearly appeared in the resistant strain Qiufeng and $\mathrm{BC}_{6}$, but was absent from Huaba35, shows some relationship with resistance to $\mathrm{DNV}-\mathrm{Z}$. QRT-PCR assures the differential expression of bmpkci. To further investigate the expression of bmpkci in other susceptible and insusceptible strains, we performed RT-PCR using two representative strains, Jingsong (susceptible) and Dong34 (resistant). bmpkci was detected in Huaba35, Jingsong, Qiufeng and Dong34, indicating that bmpkci expression occurs in many strains. However, there is tissue specific expression for this gene because BmPKCI transcript could be detected only in the midgut.

The expression level of bmpkci in both inoculated resistant strains was found to increase markedly compared to their control and the susceptible strain Huaba35. In the inoculated resistant strains, $\mathrm{BC}_{6}$ displayed a higher expression level than Qiufeng, $5.426 \pm 0.223$ versus $3.160 \pm 0.778$, this maybe because $\mathrm{BC}_{6}$ is a near isogenic strain, which possesses the predominance of heterosis (Chen 2000). No difference was observed between Huaba35 inoculated and its control. Furthermore, there is no difference among $\mathrm{BC}_{6}$ control, Qiufeng control, and Huaba35 control. Thus the differential expression of bmpkci was confirmed to be up-regulated in silkworms of the resistant strain after inoculation with BmDNV-Z.

Protein kinase $\mathrm{C}$ inhibitor (PKCI), also designated histidine triad nucleotide-binding protein1(Hint), belongs to the histidine triad (HIT) family of proteins, which contains a His-Xaa-His-Xaa-His motif, in which Xaa is a hydrophobic amino acid (Lima et al., 1997; Seraphin, 1992). A large number of PKCI homologues have been identified from a diverse number of organisms, including plants, mycoplasma, bacteria, yeast, and mammals (Robinson \& Aitken, 1994; Seraphin, 1992).

PKCI was originally identified as a bovine protein that could inhibit the in vitro phospholipid and $\mathrm{Ca}^{2+}$-dependent kinase activity of bovine brain PKC (Rane et al., 1989). Recent studies indicate that PKCI knockout mice display increased susceptibility to carcinogenicity, suggesting that PKCI may normally play a tumor suppressor role ( $\mathrm{Su}$ et al., 2003). Guang et al. (2004) provided evidence that mPKCI (murine PKCI) can inhibit PKCrelated phosphorylation of MOR ( $\mu$-opioid receptors), which suggests that PKCI could play an important role in the regulation of neurotransmitter receptors. However, the phosphatic relevance of the latter activity and its possible role in virus suppression is unknown. There is also evidence that PKCI plays a role in regulating gene transcription (Korsisaari \& Makela, 2000).

Recent studies also suggest that virus propagation is regulated by the phosphorylation of kinase. NS1, the large non-structural protein of parvovirus minute virus of mice (MVM) is a multifunctional protein regulating many tasks necessary for virus propagation. To achieve all its tasks it is differentially phosphorylated during infection, changing the biochemical profile of the polypeptide. In particular, initiation of viral DNA replication by NS1 is controlled by distinct phosphorylation events (Dettwiler et al., 1999; Lachmann et al., 2003).

In view of the above results obtained with PKCI, it ispossible that the bmpkci maybe assobiated with resistance to BmDNV-Z or involved in the expression cascade of the resistant gene. After inoculation with BmDNV-Z, the expression of bmpkci was especially high in the $\mathrm{BC}_{6}$ and Qiufeng strains, and this may contribute to inhibit the increase in BmDNV-Z, although we do not have definite evidence to prove that BmPKCI can suppress the propagation of DNV-Z. It is presumed that in resistant strains, some defense-related genes are regulated by the resistant gene, and bmpkci was involved in the defense of the silkworm against viral infection to protect. Taken together, these findings suggest that, the expression of bmpkci may relate to resistance to $\mathrm{BmDNV}-\mathrm{Z}$, but the precise bio- 
chemical function of PKCI and the possible role of PKCI in suppression of the virus remain to be determined.

ACKNOWLEDGEMENTS. This work was supported by National Basic Research Program of China (No. 2005CB121000), and National Natural Science Foundation of China (No. 30370773).

\section{REFERENCES}

Abe H., Watanabe H. \& Eguchi R. 1987: Genetical relationship between nonsusceptibilities of the silkworm, Bombyx mori, to two densonucleosis viruses. J. Seric. Sci. Jpn. 56: 443-444 [in Japanese].

Brenner C., Garrison P., Gilmour J., Peisach D., Ringe D., Petsko G.A. \& Lowenstein J.M. 1997: Crystal structures of HINT demonstrate that histidine triad proteins are GalTrelated nucleotide-binding proteins. Nat. Struct. Biol. 4: 231-238.

Bryson K., McGuffin L.J., Marsden R.L., Ward J.J., Sodhi J.S. \& Jones D.T. 2005: Protein structure prediction servers at University College London. Nucleic Acids Res. 33: W36-38.

Callard D., Lescure B. \& Mazzolini L. 1994: A method for the elimination of false positives generated by the mRNA differential display technique. Biotechniques 16: 1096-1097, $1100-1103$.

ChEN K.P. 2000: The prospects of genetics and breeding for virus-resistance in silkworm (Bombyx mori). Acta Sericol. Sin. 26: 20-24 [in Chinese].

Dettwiler S., Rommelaere J. \& NÜesch J.P.F. 1999: DNA unwinding functions of minute virus of mice NS1 protein are modulated specifically by the lambda isoform of protein kinase C. J. Virol. 73: 7410-7420.

Eguchi R., Furuta Y. \& Ninaki O. 1986: Dominant nonsusceptibility to densonucleosis virus in the silkworm, Bombyx mori. J. Sericult. Sci. Jpn. 55: 177-178.

Eguchi R., Ninaki O. \& Hara W. 1991: Genetical analysis of the nonsusceptibility to densonucleosis virus in the silkworm, Bombyx mori. J. Seric. Sci. Jpn. 60: 384-389 [in Japanese].

Florea L., Hartzell G., Zhang Z., Rubin G.M. \& Miller W. 1998: A computer program for aligning a cDNA sequence with a genomic DNA sequence. Genome Res. 8: 967-974.

GARZON S. \& KURSTAK E. 1976: Ultrastructural studies on the morphogenesis of the densonucleosis virus (parvovirus). Virology 70: 517-531.

Goldsmith M.R., Shimada T. \& Abe H. 2005: The genetics and genomics of the silkworm, Bombyx mori. Annu. Rev. Entomol. 50: 71-100.

Guang W., Wang H., Su T., Weinstein I.B. \& Wang J.B. 2004: Role of $\mathrm{mPKCI}$, a novel mu-opioid receptor interactive protein, in receptor desensitization, phosphorylation, and morphine-induced analgesia. Mol. Pharmacol. 66: 1285-1292.

Hayakawa T., Asano S., Sahara K., Iizuka T. \& Bando H. 1997: Detection of replicative intermediate with closed terminus of Bombyx densonucleosis virus. Arch. Virol. 142: 393-399.

Hu X.F., QIan Y.J. \& Wang H.L. 1984: Studies on infectivity of silkworm densonucleosis virus to some silkworm races. Acta Seric. Sin. 10: 87-90 [in Chinese].

Iwashita Y. \& Chun C.Y. 1982: The development of a densonucleosis virus isolated from silkworm larvae, Bombyx mori, of China. In Akai H., King R.C. \& Morohoshi S. (eds): Ultrastructure and Functioning of Insect Cells. Soc. Insect Cells, Tokyo, pp. 161-164.
KorsisaAri N. \& Makela T.P. 2000: Interactions of Cdk7 and Kin28 with Hint/PKCI-1 and Hnt1 histidine triad proteins. $J$. Biol. Chem. 275: 34837-34840.

Lachmann S., Rommelaere J. \& NüEsch J.P.F. 2003: Is novel PKC required to activate replicative functions of the major non-structural protein NS1 of minute virus of mice. J. Virol. 77: 8048-8060.

Li M.W., Yao Q., Hou C.X., Lu C. \& Chen K.P. 2001: Studies on RAPD markers linked to the densonucleosis refractoriness gene, nsd-Z in silkworm, Bombyx mori L. Sericologia 41: 409-415.

Li M.W., Guo Q.H., Hou C.X., Miao X.X., Xu A.Y., Guo X.J. \& HuANG Y.P. 2006: Linkage and mapping analyses of the densonucleosis non-susceptible gene nsd-Z in the silkworm Bombyx mori using SSR markers. Genome 49: 397-402.

Lima C.D., Klein M.G., Weinstein I.B. \& Hendrickson W.A. 1996: Three-dimensional structure of human protein kinase C interacting protein 1, a member of the HIT family of proteins. Proc. Natl. Acad. Sci. U. S. A. 93: 5357-5362.

Lima C.D., Klein M.G. \& Hendrickson W.A. 1997: Structurebased analysis of catalysis and substrate definition in the HIT protein family. Science 278: 286-290.

LivaK K.J. \& SChmitTGen T.D. 2001: Analysis of relative gene expression data using real-time quantitative PCR and the 2(-Delta Delta C(T)) Method. Methods 25: 402-408.

Needleman S.B. \& Wunsch C.D. 1970: A general method applicable to the search for similarities in the amino acid sequence of two proteins. J. Mol. Biol. 48: 443-453.

Qian Y.J., Hu X.F., Wang Y.X. \& Guo X.J. 1989: Serological diagnoses of the densonucleosis disease of Bombyx mori. Acta Seric. Sin. 15: 217-222.

QIN J. \& YI W.Z. 1996: Genetic linkage analysis of nsd-Z, the nonsusceptibility gene of Bombyx mori to the Zhenjiang (China) strain densonucleosis virus. Sericologia 36: 241-248.

Rane S.G., Walsh M.P., McDonald J.R. \& Dunlap K. 1989: Specific inhibitors of protein kinase $\mathrm{C}$ block transmitterinduced modulation of sensory neuron calcium current. Neuron 3: 239-245.

Robinson K. \& AitKen A. 1994: Identification of a new protein family which includes bovine protein kinase $\mathrm{C}$ inhibitor-1. $J$. Biochem. 304: 661-664.

SeKI H. 1984: Mode of inheritance of the resistance to the infection with the densonucleosis virus (Yamanashi isolate) in the silkworm, Bombyx mori. J. Sericult. Sci. Jpn. 53: 472-475.

SERAPHIN B. 1992: The HIT protein family: a new family of proteins present in prokaryotes, yeast and mammals. DNA Seq. 3: 177-179.

Siegl G. \& Tratschin J.D. 1987: Parvoviruses: Agents of distinct pathogenic and molecular potential. FEMS Microbiol. 46: $433-$

Su T., Suzui M., Wang L., Lin C.S., Xing W.Q. \& Weinstein I.B. 2003: Deletion of histidine triad nucleotide-binding protein $1 / \mathrm{PKC}$-interacting protein in mice enhances cell growth and carcinogenesis. Proc. Natl. Acad. Sci. U. S. A. 100: 7824-7829.

Watanabe H. 2002: Genetic resistance of the silkworm, Bombyx mori to viral diseases. Curr. Sci. 83: 439-446.

Watanabe H. \& Maeda S. 1978: Genetic resistance to peroral infection with a densonucleosis virus in the silkworm, Bombyx mori. J. Sericult. Sci. Jpn 47: 209-214.

Watanabe H. \& Maeda S. 1981: Genetically determined nonsusceptibility of the silkworm, Bombyx mori, to infection with a densonucleosis virus (Densovirus). J. Invertebr. Pathol. 38: 370-373. 
Watanabe H., Kawase S., Shimizu T. \& Seki H. 1986: Difference in serological characteristics of densonucleosis viruses in the silkworm, Bmobyx mori. J. Sericult. Sci. Jpn. 55: $75-76$.

Zegzouti H., Marty C., Jones B., Bouquin T., Latch'e A., Pech J.C. \& BouzAYEN M. 1997: Improved screening of cDNAs generated by mRNA differential display enables the selection of true positives and the isolation of weakly expressed messages. Plant Mol. Biol. Rep. 15: 236-245.

Received January 18, 2007; revised and accepted March 13, 2007 